\title{
Perspectivas para la enseñanza de derechos humanos en la universidad
}

Danny Ramírez Ayérdiz

Recibido 02.07.2014/Aprobado: 10.08.2014

\section{RESUMEN}

La enseñanza de los derechos humanos es una responsabilidad fundamental de los sistemas de educación, obligación cargada a los Estados desde la internacionalización de los derechos humanos (1948). El actual contexto global y local, hace requerir una revisión de los contenidos, enfoques y metodologías tradicionales de los programas académicos de derechos humanos para la formación de profesionales humanistas preparados para la interacción en sociedades democráticas.

Palabras clave: derechos humanos, educación tradicional, universidad.

\section{ABSTRACT}

The teaching of human rights is a fundamental responsibility of education systems, duty in charge of the States from the internationalization of human rights (1948). The current global and local context requires a review of the content, approaches and traditional methodologies of the academic programs in human rights for the training of professional humanists prepared for interaction in democratic societies.

Key words: human rights, traditional education, university.
$\mathrm{D}$ esde que en 1948 se inaugura la etapa de la internacionalización de los derechos humanos ${ }^{2}$, con la proclamación del instrumento más conocido, respetado y aceptado en la materia, la Declaración Universal de los Derechos Humanos ${ }^{3}$, con ella, también se da inicio al estudio de los derechos humanos, desde una perspectiva autónoma, ${ }^{4}$ necesaria para construir, en las nuevas generaciones de gobernantes y gobernados, una consciencia del más alto respeto posible por la persona humana, como garantía de no repetición de las crueldades ejecutadas en el marco de la detestable Segunda Guerra Mundial. La internacionalización supuso que el estudio de los derechos humanos también fuese una obligación permanente a cargo de los Estados, como garantía fundamental para el goce colectivo de derechos. ${ }^{5}$

Ahora bien, la crisis humanitaria que vive el mundo, el afirmamiento de sistemas autoritarios que restringen derechos, la dificultad global de valores, y en el contexto de nuestra América Latina, la desigualdad y las gigantescas brechas sociales, el regreso de algunos fenómenos autoritarios, la destrucción del funcionalismo económico del Estado a través del neoliberalismo, y la reelección de gobiernos populistas con records sistemáticos de violación de derechos, evidencia el desinterés de los sistemas, estructuras y figuras del actual sistema de poder en transformar progresivamente a la actual sociedad, en una sociedad de derechos. Lo anterior se ve con claridad en los sistemas de educación.

1 Docente Investigador del Instituto Centroamericano de Estudios Jurídicos y Políticos, ICEJP-UPOLI. Docente de Derechos Humanos de la Escuela de Ciencias Jurídicas y Políticas de la UPOLI. Colaborador: Jerson Cerda Tijerino, asistente de investigación del ICEJP-UPOLI. Correos de contacto: investigador-icejp2@upoli.edu.ni_ I dannyramirezayerdiz@gmail.com

2 La doctrina coincide en que la internacionalización, es una etapa de la evolución histórica de los derechos humanos. Esta etapa se caracteriza por elevar la discusión, defensa, promoción y protección de los derechos humanos de la esfera nacional a la esfera internacional, incentivada por el horror de los grandes crímenes cometidos en la primera y segunda guerras mundiales por los propios Estados, y en consecuencia, por la ineficacia y la despreocupación de éstos por asumir, a nivel interno, un verdadero compromiso con la protección efectiva de las personas sujetas a su jurisdicción.

3 Adoptada y proclamada por la Asamblea General en su resolución 217 A (III), de 10 de diciembre de 1948.

4 Para profundizar sobre el debate teórico acerca de los derechos humanos como ciencia, léase: Fuertes-Planas Aleix, C. (2014): Hacia una ciencia de los derechos humanos. Historia y Comunicación Social. Vol. 19. Núm. Especial Enero. Págs. 221-233.

5 La UNESCO, como agencia especializada sobre educación, comparte el mandato de promover la educación en derechos humanos, mandato al que ha dado seguimiento a través de destacables resoluciones, recomendaciones y declaraciones, alentado a los Estados a cumplir con esta obligaciones: Declaración de la 44a reunión de la Conferencia Internacional de Educación Ginebra, Suiza, octubre de 1994 Ratificada por la Conferencia General de la UNESCO en su 28a reunión, París, Francia, noviembre de 1995; Recomendación sobre la Educación para la Comprensión, la Cooperación y la Paz Internacionales y la Educación relativa a los Derechos Humanos y las Libertades Fundamentales, Conferencia General de la Organización de las Naciones Unidas para la Educación, la Ciencia y la Cultura, reunida en París del 17 de octubre al 23 de noviembre de 1974, en su 18a reunión; Plan de Acción Integrado sobre la Educación para la Paz los Derechos Humanos y la Democracia aprobado por la Conferencia General de la UNESCO en su $28^{\mathrm{a}}$ reunión, París, Francia, noviembre de 1995. 


\section{La enseñanza en derechos humanos en los sistemas de educación}

El contexto nicaragüense en el que se enseña derechos humanos, ${ }^{6}$ no es menos desalentador que el contexto hemisférico. En el sistema de educación primaria y secundaria, aun adolece de contendidos expresos o de ejes que se hagan sentir en la formación del estudiante y peor aún: la colectiva docente es carente de experiencias concretas y sistemáticas de formación en la materia. ${ }^{7}$ De ahí, que cuando el estudiante llega a los salones universitarios, considere que la asignatura "derechos humanos", en la educación superior -que no está exenta de la crisis educativa de derechos humanos-, no es más que una asignatura de relleno, locuras o inventos de las universidades que en nada servirá a su desempeño profesional.

\begin{tabular}{|l|l|}
\hline \multicolumn{2}{|c|}{ Algunos mitos sobre la asignatura de derechos humanos } \\
\hline Mito & Realidad \\
\hline La clase es de relleno. & Es necesaria para la formación humanística. \\
\hline Cualquiera puede ser docente de DDHH & La disciplina tiene particularidades teóricas que requiere su estudio previo y detallado. \\
\hline Es una clase solo para abogados. & $\begin{array}{l}\text { La universalidad de los derechos humanos y su necesidad para la sociedad, implica que sea del } \\
\text { conocimiento de todos/as. }\end{array}$ \\
\hline Es una lección de ética/moral más. & $\begin{array}{l}\text { Los estudios de derechos humanos trascienden los enfoques éticos o morales. Su plena expansión, } \\
\text { permite su estudio a partir de referentes teóricos propios del DIDH. }\end{array}$ \\
\hline Puede diseñarla cualquiera. & $\begin{array}{l}\text { Si bien es cierto, la interdisplinariedad es valiosa en los estudios de derechos humanos, la disciplina } \\
\text { tiene particularidades teóricas que requiere su estudio previo y detallado. }\end{array}$ \\
\hline $\begin{array}{l}\text { Debe estudiarse desde la perspectiva } \\
\text { constitucional }\end{array}$ & $\begin{array}{l}\text { Los estudios de derechos humanos, trascienden a los estudios de derechos constitucionales, los } \\
\text { que retoma pero no depende de ellos para razonar su existir. }\end{array}$ \\
\hline $\begin{array}{l}\text { Cualquiera que conozca de leyes, en el caso } \\
\text { de la asignatura para abogados, puede ser } \\
\text { docente de derechos humanos. }\end{array}$ & $\begin{array}{l}\text { En el ámbito jurídico, la disciplina depende del DIDH y, por consiguiente, del Derecho } \\
\text { Internacional. El docente debe conocer aspectos propios de la disciplina referida. }\end{array}$ \\
\hline
\end{tabular}

Ante expresiones así, sobre la experiencia formativa en derechos humanos desde la universidad es necesario revisar ciertas perspectivas y abordajes en cuanto a contenido, metodologíayaccióninvestigativa que se han usado tradicionalmente para enseñar derechos humanos que no necesariamente se han traducido en la formación de "...sujetos democráticos y libres, conscientes de su ${ }^{\ddots}$; responsabilidad social", que logren la autorrealización "intelectual, moral y profesional", que algunas instituciones de educación superior, pretenden. ${ }^{9}$

\section{Los contenidos de los programas de derechos humanos}

Los programas de derechos humanos, se han formulado adaptados a los enfoques basados en la metodología tradicional de educación: memorística, maestrocentrista, receptiva, superficial, alienadora y dogmática, lo que ha dado como resultado una educación en derechos humanos asentada en visiones pétreas sobre una realidad inmóvil, que responde a idealismos recurrentes y combates teóricos eternos, ajenos al debate sinérgico y al dinamismo contemporáneo, en el que debe estar inmerso el estudiante para ser factor coherente del

6 Relacionar Ley de Promoción del Estudio de los DDHH y la Cn. Política.

7 El profesor Erwin Silva, sobre las virtudes de una formación en derechos humanos para el magisterio nacional, nos dice: "[a]sí que la educación en derechos humanos debe establecerse en el sistema educativo nacional, empezando con la capacitación permanente del magisterio en esta materia que conduce a prevenir la violencia antes que reprimirla o reproducirla. Un vasto y preciso Plan Nacional de Educación en Derechos Humanos nos daría respuesta a tantos problemas y conflictos que no se gestionan por falta de capacidad de los actores sociales". Educación en derechos humanos, El Nuevo Diario. 25 de junio de 2010.

8 DIDH: Derecho Internacional de los Derechos Humanos.

9 Erwin Silva, Derechos Humanos, Historia, Fundamentos y Textos (Managua: Instituto Martin Luther King UPOLI) p. 39. 
cambio social desde la perspectiva de la conciencia de derechos. Es así como los programas tradicionales de derechos humanos, contienen cuatro grandes apartados: concepto, fundamentos y evolución de derechos humanos; generaciones de derechos humanos; derechos humanos y Constitución Política y derechos humanos y justicia penal. El abordaje es el siguiente:

\begin{tabular}{|c|c|c|}
\hline Contenido & $\begin{array}{c}\text { Abordaje teórico } \\
\text { tradicional }\end{array}$ & Críticas \\
\hline $\begin{array}{l}\text { Concepto, } \\
\text { fundamentos } \\
\text { y evolución } \\
\text { de derechos } \\
\text { humanos }\end{array}$ & $\begin{array}{l}\text { Presentación de los } \\
\text { derechos humanos, } \\
\text { desde una perspectiva } \\
\text { abstracta, interna, infra } \\
\text { legal, propiamente } \\
\text { espiritualista. Una } \\
\text { evolución de derechos, } \\
\text { a partir de las grandes } \\
\text { fechas del poder y no } \\
\text { del pueblo. }\end{array}$ & $\begin{array}{l}\text { El enfoque tradicional } \\
\text { plantea un estudio } \\
\text { conceptual subjetivo, } \\
\text { planteando los derechos } \\
\text { como aspiraciones } \\
\text { propiamente éticas y } \\
\text { no como necesidades } \\
\text { humanas, lo que pierde } \\
\text { de vista a sujetos } \\
\text { titulares y obligados } \\
\text { en el cumplimiento de } \\
\text { derechos. }\end{array}$ \\
\hline $\begin{array}{l}\text { Generaciones } \\
\text { de derechos } \\
\text { humanos }\end{array}$ & $\begin{array}{lr}\text { Estudio } & \text { lineal } \\
\text { y } & \text { memorístico } \\
\text { de los derechos } \\
\text { humanos, a partir } \\
\text { de los instrumentos } \\
\text { internacionales de } \\
\text { cada generación. Se } \\
\text { suele estudiar derecho } \\
\text { por derecho. }\end{array}$ & $\begin{array}{l}\text { Un estudio abstracto } \\
\text { de derechos, a partir } \\
\text { de instrumentos sin } \\
\text { acercamiento a la } \\
\text { realidad local y global. }\end{array}$ \\
\hline $\begin{array}{l}\text { Derechos } \\
\text { humanos y } \\
\text { Constitución } \\
\text { Política }\end{array}$ & $\begin{array}{lrr}\text { Se } & \text { estudian } & \text { los } \\
\text { derechos } & \text { humanos } \\
\text { como } & \text { sinónimos } \\
\text { de los } & \text { derechos } \\
\text { fundamentales, es } \\
\text { decir, los } & \text { establecidos } \\
\text { en las cartas } & \text { magnas. }\end{array}$ & $\begin{array}{l}\text { Hay una concentración } \\
\text { excesiva en los derechos } \\
\text { constitucionales y hay } \\
\text { confusión en considerar } \\
\text { que solo éstos, son } \\
\text { derechos humanos. }\end{array}$ \\
\hline $\begin{array}{l}\text { Derechos } \\
\text { humanos y } \\
\text { justicia penal }\end{array}$ & 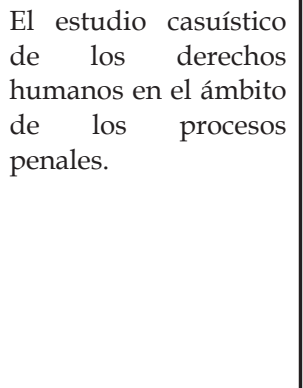 & $\begin{array}{l}\text { Se reduce la aplicabilidad } \\
\text { de los derechos } \\
\text { humanos al aspecto } \\
\text { penal, ignorando a otras } \\
\text { situaciones que suelen } \\
\text { darse en el marco de la } \\
\text { sociedad democrática: } \\
\text { libre expresión, } \\
\text { protección de grupos, } \\
\text { desigualdades sociales } \\
\text { etc. }\end{array}$ \\
\hline
\end{tabular}

En el ánimo de contribuir a la formación de profesionales sensibles con la crisis de la sociedad del desconocimiento de derechos, es necesario replantear los contenidos de nuestros programas de estudio en derechos humanos, los que deben ser capaces -junto a otras asignaturas humanísticas- de adecuarse a la realidad global y sobre todo local, en la que se moverá el fututo profesional. Nuestros programas universitarios de derechos humanos deben generar competencias habilitantes que permitan, a las y los estudiantes, sentirse parte del fenómeno y capaces de generar respuestas a éste; por lo que, el programa de derechos humanos, debe ser una experiencia de contexto, cercano al estudiante, cuyos contenidos refleje la cotidianeidad de las violaciones de derechos humanos. ${ }^{10}$

Se considera que un programa coherente con los fines señalados en el párrafo anterior debe partir de cuatro grandes apartados: 1. Aspectos generales de los derechos humanos. 2. Mecanismos jurídicos nacionales de protección de derechos humanos. 3. Derechos humanos en el ámbito internacional. 5. Derechos humanos de grupos en situación de vulnerabilidad. El abordaje propuesto, es el siguiente:

\begin{tabular}{|l|l|}
\hline Contenido & Abordaje teórico propuesto \\
\hline $\begin{array}{l}\text { Aspectos } \\
\text { generales de } \\
\text { los derechos } \\
\text { humanos }\end{array}$ & $\begin{array}{l}\text { Se estudia los aspectos introductorios, desde una } \\
\text { perspectiva de realidad partiendo de que toda } \\
\text { persona tiene una noción de lo que son derechos } \\
\text { humanos. La naturaleza de los derechos, se } \\
\text { presentan como necesidades existenciales y no } \\
\text { como valores abstractos. La evolución histórica } \\
\text { se estudia desde la necesidad de reconocer los } \\
\text { derechos en cada sociedad, enfocados en la } \\
\text { realidad latinoamericana y nacional. }\end{array}$ \\
\hline $\begin{array}{l}\text { Mecanismos } \\
\text { jurídicos } \\
\text { nacionales de } \\
\text { protección } \\
\text { de derechos } \\
\text { humanos }\end{array}$ & $\begin{array}{l}\text { Se estudia los principales medios que las normas } \\
\text { legales han establecido para conocer y resolver } \\
\text { violaciones de derechos humanos en todos los } \\
\text { ámbitos, así como la eficacia que estos medios } \\
\text { proveídos por la ley nacional, suelen tener en la } \\
\text { práctica, a partir de la experiencia de las y los } \\
\text { estudiantes. Se prueba la aplicabilidad de los } \\
\text { derechos humanos en todos los ámbitos de una } \\
\text { sociedad democrática. }\end{array}$ \\
\hline
\end{tabular}

10 El profesor Erwin Silva, sobre el papel de las universidades en los procesos de derechos humanos, nos dice: "[l]as universidades, por ejemplo, pueden abrirse a la sociedad para enseñar qué son y cómo evolucionan los derechos humanos para respetarlos, lo mismo que para prevenir y resolver pacíficamente los conflictos. Si no conocemos los derechos humanos cómo vamos a defenderlos. Por lo tanto hay que aprenderlos; debemos tener una educación básica en los derechos humanos y las libertades fundamentales.". Educación en derechos humanos, El Nuevo Diario. 25 de junio de 2010. 


\begin{tabular}{|l|l|}
\hline Contenido & Abordaje teórico propuesto \\
\hline $\begin{array}{l}\text { Derechos } \\
\text { humanos } \\
\text { en el ámbito } \\
\text { internacional }\end{array}$ & $\begin{array}{l}\text { Como consecuencia de la temática anterior, } \\
\text { se analizan los mecanismos subsidiarios que } \\
\text { ha establecido el Derecho Internacional de los } \\
\text { Derechos Humanos para la defensa de derechos } \\
\text { humanos, ante la falta de respuesta estatal. }\end{array}$ \\
\hline $\begin{array}{l}\text { Derechos } \\
\text { humanos de } \\
\text { grupos en } \\
\text { situación de } \\
\text { vulnerabilidad }\end{array}$ & $\begin{array}{l}\text { En lugardel enfoque de estudio por generaciones } \\
\text { o de la metodología de estudio en abstracto } \\
\text { derecho a derecho, se propone, el estudio de } \\
\text { la situación de derechos de grupos sociales } \\
\text { especialmente vulnerables. Este abordaje } \\
\text { permite un estudio holístico, integral, pues, } \\
\text { acerca al estudiante con la realidad que vive } \\
\text { cada grupo en lo local y global, determinando } \\
\text { los derechos especialmente violentados } \\
\text { como patrones sistemáticos generadores de } \\
\text { su vulnerabilidad y las normas nacionales e } \\
\text { internacionales que protegen estos grupos. }\end{array}$ \\
\hline
\end{tabular}

Con los anteriores grandes apartados, se esperarían cuatro resultados del estudiante:

Ha comprendido y exterioriza los derechos humanos como inherentes, pero también como necesidades existenciales urgentes para la supervivencia global e individual en un contexto de aparente peligro de extinción de la humanidad ante los conflictos bélicos, las pandemias transnacionales, la generalización de la pobreza extrema y la desvalorización de la democracia como mejor método para vivir en comunidad.

Domina y puede aplicar, los mecanismos nacionales -instituciones y leyes- previstos para la defensa de los derechos humanos.

Domina y comprende la existencia de mecanismos internacionales, como vía alterna y subsidiaria, para la protección de derechos humanos, ante el silencio, inoperancia, complicidad o impunidad de las estructuras estatales.

Comprende la situación de los principales grupos en situación de vulnerabilidad y los patrones de violación de derechos humanos que causan su desprotección social.

\begin{tabular}{|c|c|}
\hline \multicolumn{2}{|c|}{ Propuesta de contenidos del programa de derechos humanos ${ }^{11}$} \\
\hline Unidades & Contenido temático \\
\hline $\begin{array}{l}\text { UNIDAD I } \\
\text { ASPECTOS GENERALES } \\
\text { DE LOS DERECHOS } \\
\text { HUMANOS }\end{array}$ & $\begin{array}{l}\text { Concepto. } \\
\text { Antecedentes históricos. } \\
\text { Concepto, ámbito de validez. } \\
\text { Fundamento filosófico. } \\
\text { Tipología y características. } \\
\text { Características. } \\
\text { Instrumentos que contienen derechos } \\
\text { humanos. }\end{array}$ \\
\hline $\begin{array}{l}\text { UNIDAD II } \\
\text { M E C A N I S M O S } \\
\text { N A C I O N A L E S } \\
\text { JURÍDICOS } \\
\text { INSTITUCIONALES DE } \\
\text { PROTECCIÓN DE LOS } \\
\text { DERECHOS HUMANOS }\end{array}$ & $\begin{array}{l}\text { Titularidad de derechos humanos. Sujeto } \\
\text { activo y pasivo. } \\
\text { ¿Qué es una violación de derechos humanos? } \\
\text { Sociedad democrática y derechos humanos. } \\
\text { La teoría de la responsabilidad internacional de } \\
\text { los Estados en materia de derechos humanos. } \\
\text { Violaciones de derechos humanos en } \\
\text { Nicaragua: analizando el contexto. } \\
\text { Mecanismos nacionales de protección a los } \\
\text { Derechos Humanos: } \\
\text { Mecanismos institucionales: Los órganos del } \\
\text { Estado y de la sociedad civil. } \\
\text { Mecanismos judiciales: } \\
\text { La ley de amparo. } \\
\text { Los recursos de amparo, hábeas corpus, } \\
\text { inconstitucionalidad y protección de datos } \\
\text { personales. }\end{array}$ \\
\hline $\begin{array}{l}\text { UNIDAD III } \\
\text { DERECHOS HUMANOS } \\
\text { EN EL ÁMBITO } \\
\text { INTERNACIONAL }\end{array}$ & $\begin{array}{l}\text { Nociones generales del Derecho Internacional } \\
\text { de los Derechos Humanos } \\
\text { Auxiliares del Derecho Internacional de los } \\
\text { Derechos Humanos. } \\
\text { Derecho Internacional Humanitario, DIH } \\
\text { ¿Qué es el DIH? } \\
\text { Finalidades } \\
\text { Sujetos del DIH } \\
\text { Utilidad } \\
\text { Fuentes normativas del DIH } \\
\text { La Cruz Roja Internacional } \\
\text { Derecho Penal Internacional, DPI } \\
\text { Definición } \\
\text { Antecedentes } \\
\text { Características de los tribunales penales } \\
\text { internacionales } \\
\text { La Corte Penal Internacional } \\
\text { Ámbitos y ejercicio de la competencia de la } \\
\text { Corte. } \\
\text { Mecanismos Internacionales de Protección a } \\
\text { los Derechos Humanos: } \\
\text { Sistema Universal de Protección a los Derechos } \\
\text { Humanos. } \\
\text { El Sistema Europeo y el Sistema Africano. } \\
\text { Sistema Interamericano de Derechos } \\
\text { Humanos. }\end{array}$ \\
\hline
\end{tabular}

11 El programa propuesto, es producto de la experiencia profesional /docente de los maestros Ana Margarita Vijil y Danny Ramírez Ayérdiz, autor de este artículo en la Escuela de Ciencias Jurídicas y Políiticas de la UPOLI. 
Propuesta de contenidos del programa de derechos humanos ${ }^{11}$ Unidades UNIDAD IV DERECHOS HUMANOS DE GRUPOS EN CONDICIÓN VULNERABILIDAD

Contenido temático vulnerabilidad?

N Factores que potencian la vulnerabilidad.
¿Qué es un grupo en condición de

DE Exclusión, derechos humanos y vulnerabilidad. Deberes del Estado con los grupos en condición de vulnerabilidad.

Derechos humanos de grupos en especial condición de vulnerabilidad en Nicaragua. Los niños, niñas y adolescentes.

Personas privadas de libertad.

Personas indígenas y de otros grupos étnicos. Personas con discapacidad.

Personas en estado de extrema pobreza. Personas migrantes indocumentadas. Mujeres: trabajadoras del campo, trabajadoras domésticas y trabajadoras sexuales.

Personas que conviven con VIH/SIDA.

Personas miembros de la comunidad LGTTBI. Personas con discapacidad. Personas en situación de calle.

\section{La metodología activa, necesaria para una nueva enseñanza en derechos humanos}

El proceso de formación del estudiante en la post modernidad, exige que él sea sujeto pleno de la transformación de la realidad circundante y por lo tanto, la posición clásica como receptor silente de los conocimientos, es por sí desfasada y, por demás, peligrosa, si lo que pretende un sistema educativo superior determinado, es la modificación -erradicaciónde patrones, roles y antivalores socioculturales en los que están soportados los pilares del actual sistema social, carente de un enfoque de derechos.

Según el sitio web de la Universidad Peruana de Ciencias Aplicadas, la metodología activa participativa puede ser tenido como: ...una estrategia pedagógica que promueve que el alumno participe activamente del proceso de aprendizaje, como responsable de la construcción de su propio conocimiento mediante recursos didácticos como debates, discusiones grupales, talleres y aprendizaje colaborativo, entre otros. En esta dinámica el docente realiza un rol de guía facilitador, asesorando y acompañando al alumno en su aprendizaje. ${ }^{12}$

Las organizaciones civiles internacionales han manifestado la importancia de utilizar la metodología participativa activa en la enseñanza de los derechos humanos, en este sentido definen metodología participativa como:

un marco para concebir y llevar a cabo una educación que promueva la reflexión compartida, el análisis crítico, el cuestionamiento en profundidad y la resolución de problemas colectiva ${ }^{13}$.

La metodología activa participativa, es un instrumento didáctico que permite crear un ambiente en la sala de clases donde la función docente es menos dirigente y centralizadora y el estudiantado, es protagonista, a través de un aprendizaje autónomo, basado en el conocimiento e interpretación del entorno y los fenómenos sociales, propicia para el desarrollo de la asignatura de derechos humanos.

Esta metodología activa, tiene por objeto, sobre todo, centrar la atención en lo que el estudiantado hace y no en el y la docente. Por lo tanto, esta metodología es una clara contraposición al enfoque tradicional de la educación, donde prima el "magistrocentrismo", contraproducente a un enfoque de derechos. ${ }^{14}$

Esta metodología requiere y permite la aplicación de estrategias de aprendizaje ${ }^{15}$ que podrían ser útiles para conseguir los objetivos establecidos en programas de derechos humanos que se diseñen desde perspectivas

12 Universidad Peruana de Ciencias Aplicadas. Metodología Activa. Centro de información. Información disponible en el siguiente sitio: http://ci.upc.edu.pe/0/upc.aspx/servicio-alalumno/calidad-educativa/proyectos/innovacion-y-curriculo/metodologia-activa Consultado el 13 de septiembre de 2014.

13 Amnistía Internacional. Manual de facilitación. Guía para el uso de metodologías participativas en la educación en derechos humanos (Madrid: Editorial Amnistía Internacional, 2011), p. 12

14 Almudena Sánchez-Dehesa. Metodología Tradicional vs Metodología Activa-Participativa. Educación y sociedad. Información disponible en el siguiente sitio: http:/l almudenasanchez19.blogspot.com/2013/05/metodologia-tradicional-vs-metodologia.html Consultado el 13 de septiembre de 2014.

15 Rosa Urbina Zúniga, define como estrategias de aprendizaje: [EI] conjunto planificado de acciones y técnicas que conducen a la consecución de objetivos preestablecidos en el proceso de capacitación. [Didáctica para la educación continua. Unidad III: Planeamiento didáctico. Academia de Policía Walter Mendoza. Instituto de Estudios Superiores. Managua, 2014. P. 5.] 
menos tradicionales. Por lo anterior, algunas estrategias útiles en los estudios de derechos humanos, pueden ser, el estudio de casos, el debate, la mesa redonda, la simulación, la discusión libre, el cine foro, inter alia. Desde nuestra experiencia docente, ha resultado de mucha utilidad para sensibilizar al estudiante, el estudio de campo, donde los estudiantes se acercan y conviven con miembros de grupos en situación de vulnerabilidad.

Por lo tanto, es necesario que las instituciones de educación superior, y los docentes de derechos humanos, abandonen paradigmas habituales para la metodología educativa en derechos humanos; no es posible hablar de derechos humanos, en medio de docentes que imponen verdaderas dictaduras educativas. La metodología activa, se presta a la creación del debate, del pensamiento libre, de la intriga propia de un profesional formado para la interacción en una sociedad en democracia. No hay educación en derechos humanos, en medio de sistemas de educación deformantes.

\section{La producción investigativa en el aula de clases de derechos humanos}

La investigación en la asignatura de derechos humanos, debe estar orientada en lograr un profesional sensible, humanista, interesado en su contexto y en las posibilidades de alterarlo para el bienestar individual y colectivo. Ante ello, es necesario que la producción investigativa, en derechos humanos esté firmemente conectada al acercamiento con la realidad y no al debate de discusiones teóricas interminables. La investigación en derechos humanos, debe acercar al estudiante más al campo donde suceden los derechos humanos, más que encerrarlo en una biblioteca.

La investigación documental es importante en derechos humanos, pero la investigación de campo, es necesaria, urgente y fundamental porque el efecto directo es la sensibilidad del estudiante con la gente que sufre día a día los embates de la discriminación, la exclusión y el empobrecimiento; incluso, este tipo de investigación, le hace identificarse con realidades que hasta él mismo investigador estudiante es parte. Por ejemplo, la investigación de experiencias testimoniales de violencia basada en género, aproxima a estudiantes mujeres y hombres hacia los temas de equidad, observándose como parte del fenómeno especialmente si lo han vivido.

\section{Conclusión}

El sistema de educación superior, debería entrar en un proceso de reflexión sobre sus aportes al debate sobre los derechos humanos y su papel en la consolidación de estos, a través de los profesionales que envía a la sociedad. En el marco de la mercantilización de las carreras universitarias, se ha dejado como tema de molestia que mejor es no mencionar, el componente de derechos humanos. Mientras algunas universidades nicaragüenses, ya suprimieron -sin cargo de conciencia institucional- cualquier referencia de formación en derechos humanos, otras que aún lo contemplan, no han revisado la pertinencia de los contenidos curriculares de esta asignatura para adecuarlas a una realidad, donde el enfoque de derechos humanos será cada vez más necesario, en el contexto de una sociedad que requiere más opresión -y opresores- y más oprimidos, para soportar las bases de un odioso orden excluyente, desinteresado en la real, efectiva y plena autorrealización personal y colectiva, fin último de los derechos humanos.

\section{Referencias Bibliográficas}

Academia de Policia Walter Mendoza. «Didactica para la educación continua.» Unidad III: Planteamiento Didáctico. Managua, 2014.

Amnistía Internacional. Manual de Facilitación: Guía para el uso de metodologías en la educación en derechos humanos. Madrid: Editorial Amnistía Internacional, 2011.

Sanchez-Dehesa, Almudena. Educación y Sociedad. 8 de mayo de 2013. http://almudenasanchez19. blogspot.com/2013/05/metodologia-tradicionalvs-metodologia.html (último acceso: 13 de septiembre de 2014).

Silva, Erwin. Derechos Humanos, Historia, Fundamentos y Textos.Managua: Instituto Martin Luther King UPOLI, s.f.

Universidad Peruana de Ciencias Aplicadas. Universidad Peruana de Ciencias Aplicadas. s.f. http://ci.upc. edu.pe/0/upc.aspx/servicio-al-alumno/calidadeducativa/proyectos/innovacion-y-curriculo/ metodologia-activa (último acceso: 13 de septiembre de 2014). 